\title{
1-Year Post-loading of Short and Ultrashort Implants in Posterior Mandibular and Maxillary Regions
}

\author{
Noha M. EIAdI ${ }^{1}$, Hisham M. Sholkamy ${ }^{2}$, Aala'a S. Emara ${ }^{2 *}$ \\ ${ }^{1}$ Department of Surgery and Oral Medicine, National Research Centre, Cairo, Egypt; ${ }^{2}$ Department of Oral and Maxillofacial \\ Surgery, Faculty of Dentistry, Cairo University, Cairo, Egypt
}

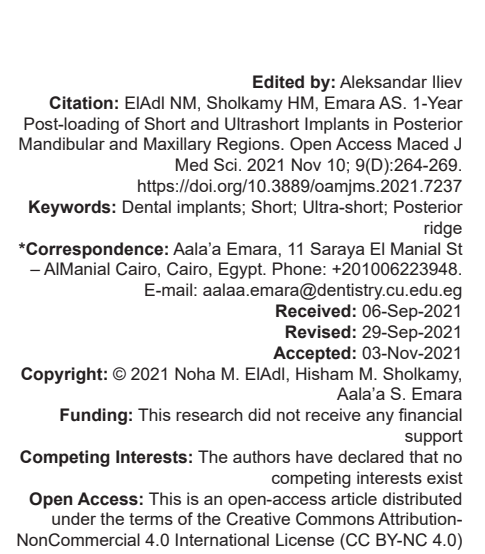

Abstract

BACKGROUND: Short implants have been proposed as an option for management of deficient alveolar ridges without the need for complex augmentation procedures.

AIM: In this study, we aim to assess the use of short and ultrashort implants for the management of deficient alveolar ridges in posterior mandibular and maxillary areas with a 1-year post-loading follow-up.

METHODOLOGY: Ten patients were recruited in this trial with a total of 14 implants to be placed. The patients al needed implants in the maxillary/mandibular posterior regions for prosthetic rehabilitation with deficient alveolar ridge heights. Implants of $5 \mathrm{~mm}$ diameter and lengths either 6 or $8.5 \mathrm{~mm}$ were to be placed in the edentulous spaces after proper radiographic assessment. Two-stage surgeries were followed with $3 / 4$ months between implant placement and loading. The follow-up lasted for a year to allow for peri-implant clinical assessment and radiographic analysis.

RESULTS: All patients showed uneventful healing and no infection, wound dehiscence or inflammation was noted. Prosthetic rehabilitation was successful and satisfactory to the patients. None of the cases showed excessive marginal bone loss and stability was maintained at acceptable levels to the end of the follow-up period.

CONCLUSION: Within the limitations of this study, short and ultrashort implants seem like a valid option for management of posterior edentulous regions with deficient ridge heights.

\section{Introduction and Review of Literature}

Historically, removable full or partial dentures have been given to edentulous patients requiring dental care to restore function and cosmetic appearance. These removable dentures, however, result in a sense of patient insecurity, decreased chewing ability and taste, and low self-esteem [1]. The high success rate of dental implants has made the switch to dental implants when indicated logical as it improved the quality of life for many patients. The rate of success appears to be linked to the quantity and quality of the bone.

Although longer implants were found to be of better results than shorter implants [2], [3]; the concept of short implants is very beneficial in certain anatomical conditions [4].

The quantity of bone especially in the posterior regions is commonly compromised due to sinus pneumatization in the maxilla and the inferior alveolar canal in the mandible. There were several approaches to manage such conditions were reported by prosthetic.

Rehabilitation or ridge surgeries when atrophy of the jaws was encountered.
More aggressive protocols call for bone grafting, accompanied by insertion of endosseous implants [4], [5], [6], [7].

In the setting of reduced alveolar bone height, the short dental implants have recently become available and give the clinicians a proactive alternative to promote prosthetic restoration in the face of anatomic limitation [8].

Various forms of standard Branemark implants (3.75 mm) for the treatment of edentulous jaws have been developed over the years, beginning with the $10 \mathrm{~mm}$ long implant in 1971 [9].

The 7-mm standard implant was introduced in 1979 due to the need for rehabilitation of such a growing number of atrophic jaws. This implant was used alone or with longer implants in edentulous jaws from the beginning, but ultimately also used in the treatment of partial edentulism [10], [11], [12], [13].

In addition, wide-diameter implants were introduced to promote the replacement of a failing standard implant and to increase the success rate in compromised circumstances [14]. To comply with two indications, the wide-diameter implant was first introduced:

Low bone quality and/or quantity and replacement of a failed standard implant [15]. 
Some authors have found that when the length of the implant was compromised for circumstances where residual alveolar height was less, wide-diameter implants were successful. Therefore, for shorter and broad-diameter implants, there was a partnership. After more than 10 years of follow-up, reconstruction of the atrophic mandible using short implants without augmentation procedures yielded a cumulative implant survival rate of $92.3 \%$ [16].

\section{Methodology}

A prospective study was designed to assess the use of short implants in the posterior mandibular and maxillary regions. A total of ten patients with a total of 14 implants were placed seven in the mandibular posterior region and seven in the maxillary posterior region. The cases included were patients with no medical conditions complicating implant placement such as uncontrolled diabetes, bleeding disorders, and complex cardiac conditions. Digital panoramic radiographs were taken to assess the ridge width and height and maxillary/mandibular ridges with insufficient height due to sinus pneumatization or inferior alveolar canal position, respectively, were included in the study provided that a minimum of $6-8 \mathrm{~mm}$ of bone height was available.

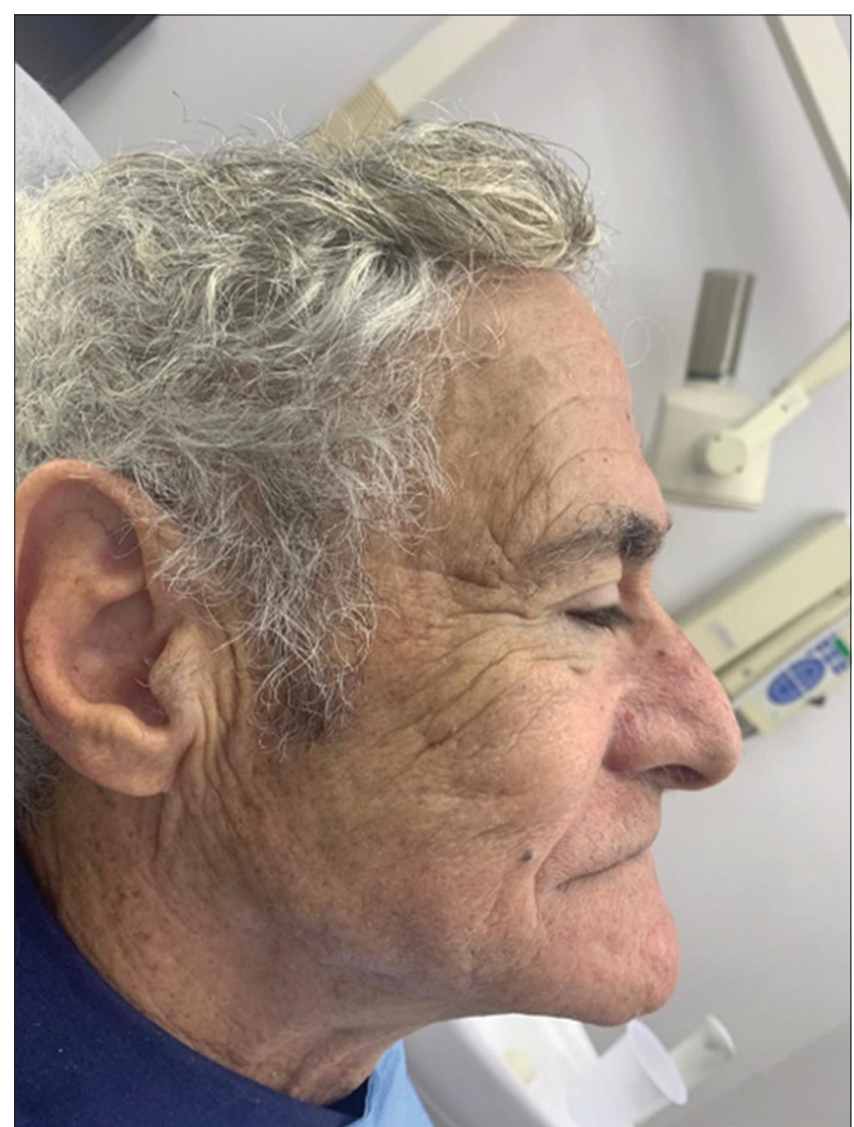

Figure 1: Photograph of one of our patients preoperatively

\section{Pre-operative preparation and assessment}

All the patients were informed about the surgical steps included in the study and the postoperative period and expected risks and complications. Written consents were obtained.

Dental and periodontal checkups were carried out to eliminate plaque, gingival inflammation, and clean periodontal pockets. Panoramic digital radiographs were ordered preoperatively to assess bone quality and quantity at the intended implant sites. The implants to be used were $6 / 8.5 \mathrm{~mm}$ long and $5 \mathrm{~mm}$ wide by Flotecno Bioart Conical implant systems ${ }^{1}$. Two-stage surgical approach was to be followed with a $3 / 4$ month interval between the stages. Figures 1 and 2 show the photographs and clinical photos of one of our patients, patient \# 4 .

\section{Surgical procedure}

The first-implant surgery was performed at least 4-5 months after extraction or in a healed socket with local anesthesia (an infiltration of $2 \%$ Ligno-caine hydrochloride monohydrate with 1:100 000 epi-nephrine acid tartrate; Duopharma Biotech, Selangor, Malaysia). A horizontal mid-crestal incision

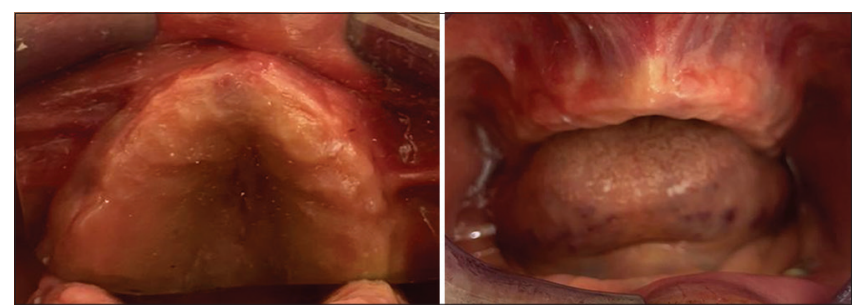

Figure 2: Intraoral photo of the maxillary and mandibular arches

and two releasing incisions were made at the sites of implant placement. The design of the incision was mostly trapezoidal, resulting in a flap which was wider at the base in an attempt to provide optimal vascular circulation. Full-thickness flaps were then reflected exposing the alveolar ridge.

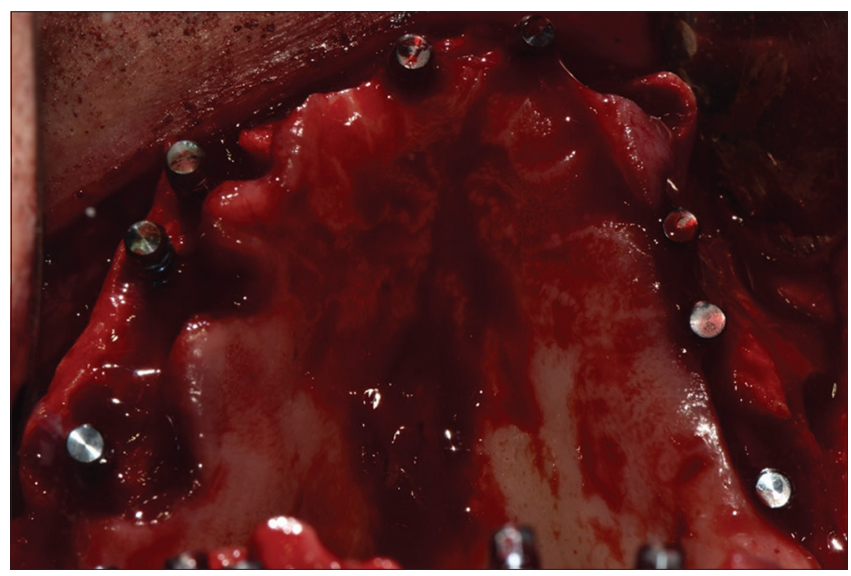

Figure 3: Intraoperative photograph of implant alignment in maxillary arch

Implant placement was performed on a disinfected region by scrubbing with betadine solution. 
Local anesthetic solution (2\% Lidocaine hydrochloride with 1:100,000 epinephrine) was injected for pain and bleeding control. A crestal and releasing incision were made using a ten Bard Parker blade. Reflection of the mucoperiosteal full thickness flap was done as routinely to expose the underling bone and locate site of implant placement. The implant drills were used sequentially to reach the required depth and width for implant placement under copious irrigation. In case of adjacent implants, a space of at least $3 \mathrm{~mm}$ was kept between them. The implant shoulder was kept subcrestal as per the manufacturer's recommendations. Once the implant was secured in position and 1ry stability confirmed, the flap was returned in position and secured in place with interrupted 3-0 silk sutures (Figure 3).

Post-operative care and instructions were followed as routinely done; antibiotics, anti-inflammatory medication, and oral hygiene maintenance were instructed to preserve an inflammation/infection free surgical site. Ten days after surgery, the patients were recalled for checkup and suture removal (Figures 4 and 5).

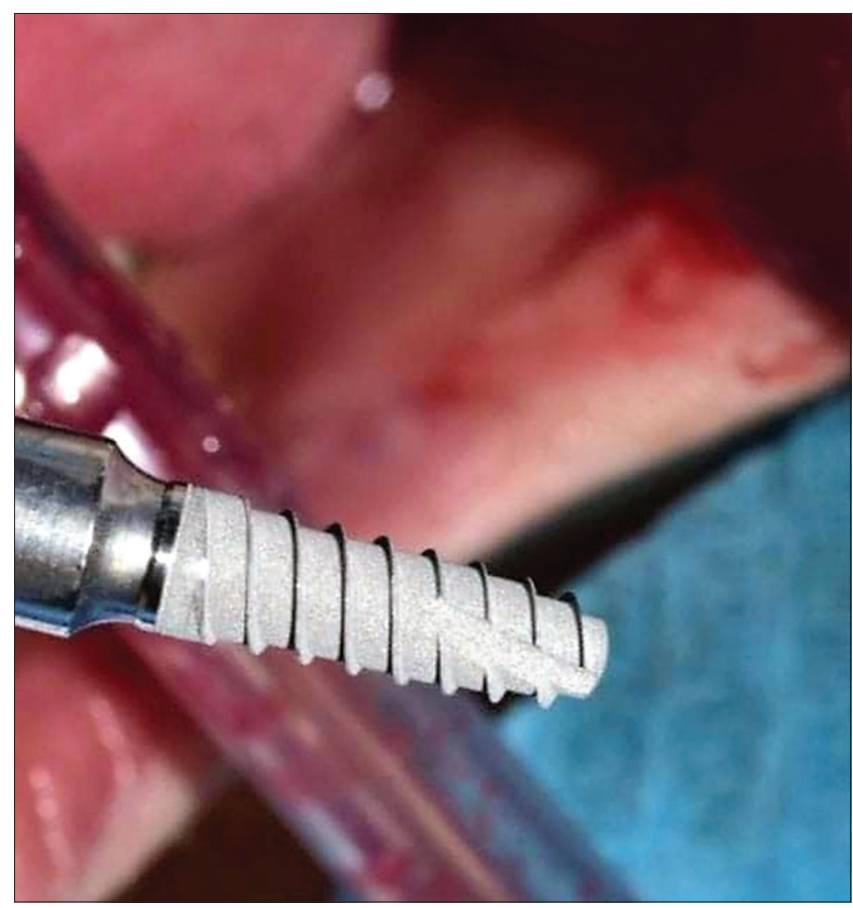

Figure 4: Implant ready for insertion

Three-four months postoperatively, the patients were recalled to check the implants healing and schedule the prosthetic loading phase. Clinically, the implant site was checked for exposure of the implant/bone, infection, inflammation, mucosal tearing, and tenderness. Once these were excluded from the study; a second panoramic radiograph was ordered and second surgery performed. Under the same antiseptic and local anesthetic measures as the first-stage, the implant sites were incised and the corresponding healing abutments attached to the exposed implants.

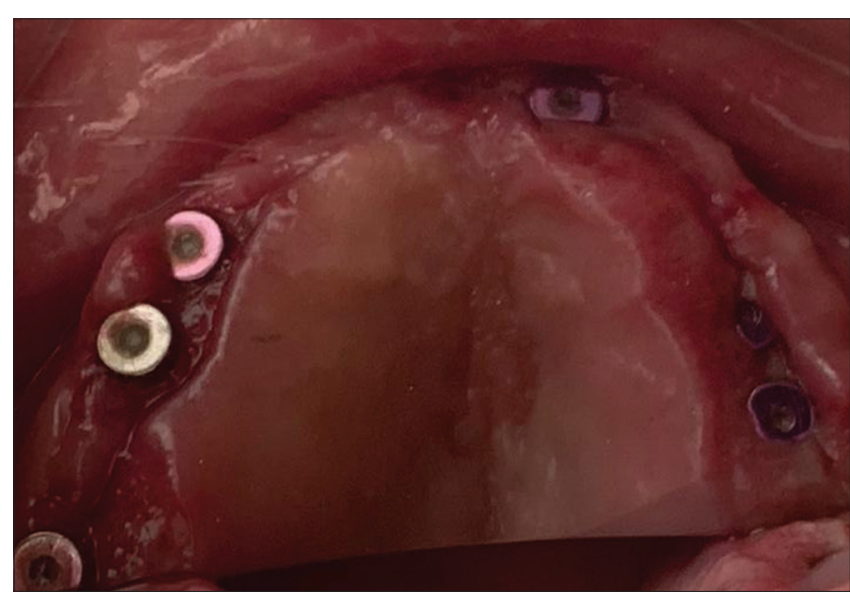

Figure 5: Healing caps fixed onto the maxillary implants

The outcomes included peri-implant clinical parameters and radiographic assessment were repeated a year after loading.

\section{Results}

Ten patients were included in this study, four males and six females with a mean age range of 39 years old. A total of 14 implants were placed with varying positions but all in the posterior region whether maxillary or mandibular. Table 1 shows the demographic data of the included cases.

Table 1: Demographic data of the included patients and the edentulous spans to be restored

\begin{tabular}{lllll}
\hline & Age & Gender & Occupation & Missing teeth to be restored/implants placed \\
\hline 1 & 53 & M & Driver & Upper Rt 7 \\
2 & 37 & F & Teacher & Lower Lt 6 \\
3 & 49 & F & Accountant & Lower Rt 5 \\
4 & 61 & M & Bank manager & Lower Rt\&Lt. 4,6 \\
5 & 42 & F & Nurse & Lower Lt 6 \\
6 & 48 & F & Housewife & Upper Lt 5 \\
7 & 42 & F & Housewife & Upper Lt 7 \\
8 & 41 & F & Housewife & Lower Rt 4 \& Lower Lt 6 \\
9 & 50 & M & Shop owner & Lower Rt 6 \\
10 & 40 & F & Teacher & Upper Lt 6 \\
\hline
\end{tabular}

All implants attained primary stability during first stage placement. Healing of all the patients was uneventful with the proper instructions delivered and followed by the patients. Patients were recalled for follow-up and suture removal 10 days postoperatively and proper healing process was confirmed. Three to four months later, the second stage surgery was planned, a panoramic radiograph ordered, the implants uncovered, and healing caps fixed in place for proper gingival formation when indicated. Prosthetic stage was started and all patients received their prostheses. Follow-up extended for a year postloading (Figures 5-8).

Assessment of the implants clinically in all of the patients showed no signs of pocketing/infection or inflammation. All radiographs also showed proper bone osseointegration. 


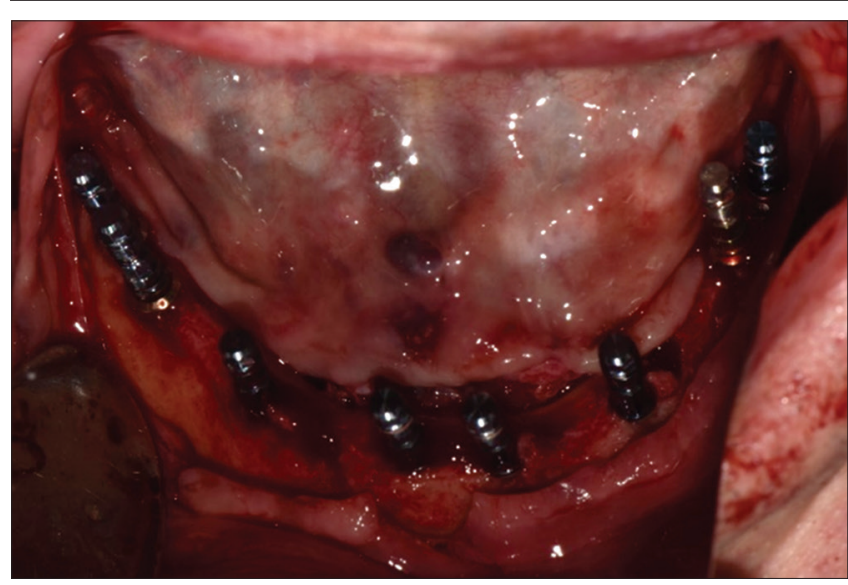

Figure 6: Mandibular implants with paralleling pins in place

\section{Discussion}

The use of short/ultra-short dental implants has recently been given a lot of attention although the actual definition of short implants is still controversial. Some authors noted than an implant shorter than $11 \mathrm{~mm}$ is considered short while others consider those shorter than ten or even eight as short. Moreover, implants shorter than $7 \mathrm{~mm}$ were considered as ultrashort [17], [18], [19]. In our present study, we considered implants $<10 \mathrm{~mm}$ and those $<7 \mathrm{~mm}$ were considered ultrashort.

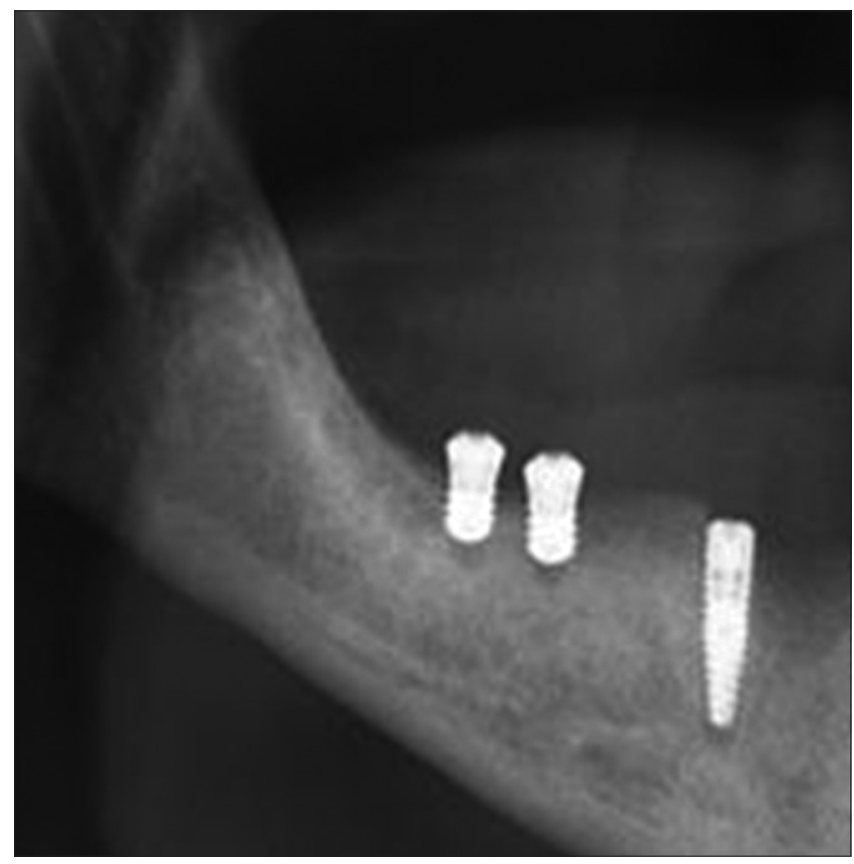

Figure 7: Panoramic radiograph showing the short implants in place before loading

Short implants have shown advantageous results especially in posterior areas where the maxillary sinus or the inferior alveolar canal may compromise the amount of bone available for implant placement. On the other hand, they have also been indicated for use rather augmentation surgeries which are costly and complex and carry higher risk of infection and morbidity in case of autogenous graft harvesting. During the present study, the use of short implants was due to age considerations or other reasons complicating complex augmentation procedures. Three of our patients refused having autograft harvest for implant placement.

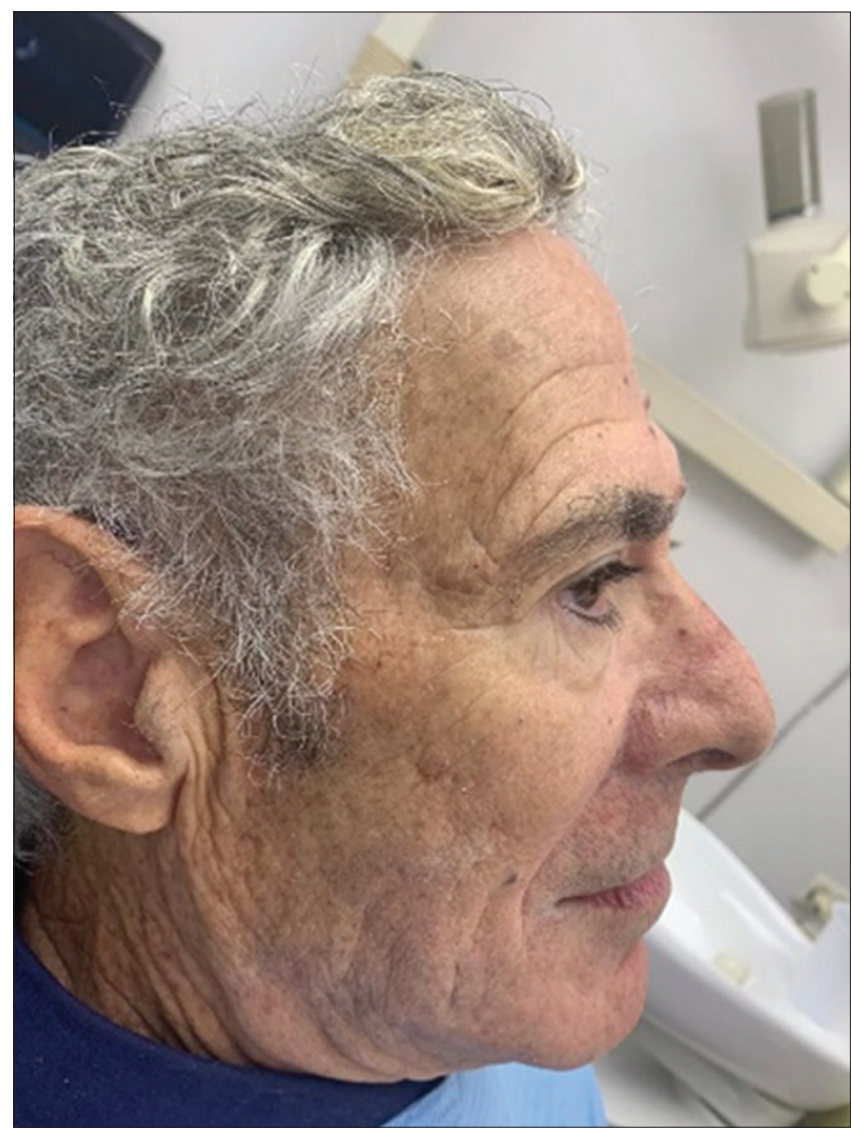

Figure 8: Photograph of the patients profile after implant loading and delivery of the final prostheses (note the improvement in vertical dimension and facial profile)

Clinical assessment of the implants 1 year after loading in the present study showed success of the prosthetic rehabilitation in all ten included cases (14 implants). The assessment aimed to primarily evaluate the masticatory function, stability of the implant, and coronal suprastructure. As reported by our study, the 1-year follow-up in all of the included cases showed successful prosthetic rehabilitation with none to minimal acceptable marginal bone loss. This was in agreement to earlier research which reported the success of short and ultrashort implants when compared to conventional length implants in the posterior region whether maxillary or mandibular [20], [21], [22].

In the present study, we fixed the diameters of the implants at $5 \mathrm{~mm}$ to reduce increasing the variables that would affect the final verdict. Implant diameter was reported to affect marginal bone loss as well and may even be the site of the earliest bone loss in the first few millimeters of bone contact [23]. This was also supported by a couple of other researches that concluded that the occlusal force is concentrated in the cervical region and less apically [24], [25]. These 
conclusions should support the argument that since short implants have less length of bone contact so more marginal bone loss is possible; this was negated by multiple studies which supported the hypotheses that the diameter of the implant is of greater impact. This supported the decision of our group to keep the diameter of all short implants at $5 \mathrm{~mm}$.

This study aims to primarily report the follow-up of use of short and ultrashort implants in mandibular and maxillary posterior regions. The limited case count makes this a simple preliminary report providing evidence for future research. Further research with larger samples and longer follow-up of different prosthetic rehabilitation cases is essential to reach a final decision on the use of such implants.

\section{References}

1. Ostman PO. Immediate/early loading of dental implants. Clinical documentation and presentation of a treatment concept. Periodontol 2000. 2008;47:90-112. https://doi. org/10.1111/j.1600-0757.2007.00244.x

\section{PMid:18412576}

2. Quirynen M, Naert I, van Steenberghe D. Fixture design and overload influence marginal bone loss and fixture success in the Brånemark system. Clin Oral Implants Res. 1992;3(3):104-11. https://doi.org/10.1034/j.1600-0501.1992.030302.x PMid: 1290790

3. Sennerby L, Roos J. Surgical determinants of clinical success of osseointegrated oral implants: A review of the literature. Int $J$ Prosthodont. 1998;11(5):408-20.

PMid:9922733

4. Schliephake H, Neukam FW, Wichmann M. Survival analysis of endosseous implants in bone grafts used for the treatment of severe alveolar ridge atrophy. J Oral Maxillofac Surg. 1997;55(11):1227-33; discussion 1233-4. https://doi. org/10.1016/s0278-2391(97)90173-7

PMid:9371112

5. Bell RB, Blakey GH, White RP, Hillebrand DG, Molina A Staged reconstruction of the severely atrophic mandible with autogenous bone graft and endosteal implants. J Oral Maxillofac Surg. 2002;60(10):1135-41. https://doi.org/10.1053/ joms.2002.34986

PMid:12378486

6. Kahnberg KE, Nilsson P, Rasmusson L. Le Fort I osteotomy with interpositional bone grafts and implants for rehabilitation of the severely resorbed maxilla: A 2-stage procedure. Int J Oral Maxillofac Implants. 1999;14(4):571-8.

PMid:10453674

7. Smedberg JI, Johansson P, Ekenbäck D, Wannfors D. Implants and sinus-inlay graft in a 1-stage procedure in severely atrophied maxillae: Prosthodontic aspects in a 3-year follow-up study. Int $J$ Oral Maxillofac Implants. 2001;16(5):668-74.

PMid:11669249

8. Gentile MA, Chuang SK, Dodson TB. Survival estimates and risk factors for failure with $6 \times 5.7-\mathrm{mm}$ implants. Int $\mathrm{J}$ Oral Maxillofac Implants. 2005;20(6):930-7.

PMid:16392351

9. Lekholm U. The branemark implant technique. A standardized procedure under continuous development. In: Tissue Integration in Oral, Orthopedic and Maxillofacial Reconstruction. United States: Quintessence Publishing Co. Inc.; 1992. p. 194-9.

10. Adell $R$, Eriksson $B$, Lekholm U, Brånemark PI, Jemt $T$. Long-term follow-up study of osseointegrated implants in the treatment of totally edentulous jaws. Int $\mathrm{J}$ Oral Maxillofac Implants. 1990;5(4):347-59. https://doi. org/10.1034/j.1600-0501.1993.040404.x

PMid:2094653

11. Jemt $T$, Lekholm $U$, Adell R. Osseointegrated implants in the treatment of partially edentulous patients: A preliminary study on 876 consecutively placed fixtures. Int J Oral Maxillofac Implants. 1989;4(3):211-7.

PMid:2700745

12. van Steenberghe $\mathrm{D}$, Lekholm $\mathrm{U}$, Bolender $\mathrm{C}$, Folmer $\mathrm{T}$, Henry P, Herrmann I, et al. Applicability of osseointegrated oral implants in the rehabilitation of partial edentulism: A prospective multicenter study on 558 fixtures. Int J Oral Maxillofac Implants. 1990;5(3):272-81.

PMid:2098330

13. Nevins M, LangerB. The successfulapplication ofosseointegrated implants to the posterior jaw: A long-term retrospective study. Int J Oral Maxillofac Implants. 1993;8(4):428-32.

PMid:8270312

14. Renouard F, Arnoux JP, Sarment DP. Five-mm-diameter implants without a smooth surface collar: Report on 98 consecutive placements. Int J Oral Maxillofac Implants. 1999;14(1):101-7. PMid: 10074759

15. Langer B, Langer L, Herrmann I, Jorneus L. The wide fixture: A solution for special bone situations and a rescue for the compromised implant. Part 1. Int J Oral Maxillofac Implants. 1993;8(4):400-8.

PMid:8270308

16. Davies JE. Mechanisms of endosseous integration. Int J Prosthodont. 1998;11(5):391-401.

PMid:9922731

17. Ravidà $A$, Barootchi $S$, Askar $H$, Suárez-López Del Amo $F$, Tavelli L, et al. Long-term effectiveness of extra-short ( $\leq 6 \mathrm{~mm})$ dental implants: A systematic review. Int J Oral Maxillofac Implants. 2019;34(1):68-84. https://doi.org/10.11607/jomi.6893 PMid:30695086

18. Yanes CP, Mesegué MD, López JL, Obispo CA, Roig AM. Short dental implants in atrophic jaws rehabilitation. Update. Avances Periodoncia Implantol Oral. 2017;29:23-30. https://doi. org/10.1016/j.piro.2015.10.003

19. Papaspyridakos P, Souza A, Vzouras K, Gholami H, Pagni S, Weber PH. Survival rates of short dental implants $(\leq 6 \mathrm{~mm})$ compared with longer than $6 \mathrm{~mm}$ in posterior jaws areas: A meta-analysis. Clin Oral Implant Res. 2018;29 Suppl 16:8-20. https://doi.org/10.1111/clr.13289 PMid:30328206

20. Malmstrom H, Gupta B, Ghanem A, Cacciato R, Ren $Y$, Romanos GE. Success rate of short dental implants supporting single crowns and fixed bridges. Clin Oral Implant Res. 2016;27(9):1093-8. https://doi.org/10.1111/clr.12693 PMid:26391214

21. Tabrizi R, Arabion H, Aliabadi E, Hasanzadeh F. Does increasing the number of short implants reduce marginal bone loss in the posterior mandible? A prospective study. $\mathrm{Br} \mathrm{J}$ Oral Maxillofac Surg. 2016;54(7):731-5. https://doi.org/10.1016/j. bjoms.2016.04.010

PMid:27131984

22. Sierra-Sánchez JL, García-Sala-Bonmatí F, MartínezGonzález A, García-Dalmau C, Mañes-Ferrer JF, Brotons-Oliver A. Predictability of short implants $(<10 \mathrm{~mm})$ as a treatment 
option for the rehabilitation of atrophic maxillae. A systematic review. Med Oral Patol Oral Cir Bucal. 2016;21(3):e392-402. https://doi.org/10.4317/medoral.20949

PMid:26946199

23. Slotte C, Grønningsaeter A, Halmøy AM. Four-millimeter implants supporting fixed partial dental prostheses in the severely resorbed posterior mandible: Two-year results. Clin Implant Dent Relat Res. 2012;14 A Suppl 1:e46-58. https://doi. org/10.1111/j.1708-8208.2011.00346.x

PMid:21599827
24. Loyola-González P, Torassa D, Domínguez A. Comparative study on the behaviour and tension distribution in short and standard dental implants in the back of the upper jaw. Rev Clin Periodoncia Implantol Rehabil Oral. 2016;9:36-41. https://doi. org/10.1016/j.piro.2015.10.003

25. Anitua E, Piñas L, Begoña L, Orive G. Long-term retrospective evaluation of short implants in the posterior areas: Clinical results after 10-12 years. J Clin Periodontol. 2014;41(4):404-11 . https://doi.org/10.1111/jcpe.12222

PMid:24354567 